\title{
Polymorphisms of the NADPH Oxidase p22phox Gene in a Caucasian Population with Intracranial Aneurysms
}

\author{
Dietmar Krexa Andreas Zieglerc Inke R. König ${ }^{c}$ Hans K. Schackert ${ }^{b}$ \\ Gabriele Schackert ${ }^{a}$
}

Departments of a Neurosurgery and bSurgical Research, University Hospital Carl Gustav Carus, University of Technology, Dresden, and 'Institute of Medical Biometry and Statistics, Medical University of Lübeck, Lübeck, Germany

\section{Key Words}

Polymorphism (genetics) • Risk factors · Aneurysm • Oxygen radical

\begin{abstract}
Background: Vascular remodeling generated by reactive oxygen species contributes to aneurysm formation. The NADPH oxidase system is a major source of superoxide anion not only in phagocytes, but also in endothelial and vascular smooth muscle cells. Polymorphisms of p22phox, an essential component of the NADPH oxidase system, are found to be associated with atherosclerosis, while a recent study found a significant association between the $214 \mathrm{C}>\mathrm{T}$ polymorphism and the occurrence of ischemic cerebrovascular disease. We conducted a case-control study to investigate the relationship of five polymorphisms of the p22phox gene and the occurrence of cerebral aneurysms. Methods: The study population consisted of 113 patients with intracranial aneurysms and 53 control subjects. The $214 \mathrm{C}>\mathrm{T}$ polymorphism was investigated by restriction fragment length polymorphism analysis, while polymorphisms 381T $>C, 480 \mathrm{G}>\mathrm{A}$, $521 \mathrm{C}>\mathrm{T}$, and ${ }^{*} 24 \mathrm{~A}>\mathrm{G}$ were analyzed by direct sequencing of exon 6 and adjacent intronic sequences. Results: The analysis of a primary study sample comprising 35
\end{abstract}

\section{KARGER}

Fax +41613061234

E-Mail karger@karger.ch

www.karger.com (c) 2003 S. Karger AG, Basel

1015-9770/03/0164-0363\$19.50/0

Accessible online at:

www. karger.com/ced cases and 28 controls failed to show a significant association between any of the five polymorphisms and the occurrence of intracranial aneurysms using both allele frequencies and genotypes (all nominal $p>0.05$ ). Although there was a deviation from Hardy-Weinberg equilibrium in cases at the $521 \mathrm{C}>\mathrm{T}$ locus (nominal $\mathrm{p}<$ $0.05)$, this could not be confirmed in a second study sample of 78 patients. Haplotypes were constructed regarding three frequent polymorphisms $(214 \mathrm{C}>\mathrm{T}, 521 \mathrm{C}>\mathrm{T}$, and *24A $>\mathrm{G}$ ); haplotype frequencies in cases and controls were not significantly different. Conclusion: Although polymorphisms of the p22phox gene located in the coding region and the $3^{\prime}$-untranslated region were reported to be associated with atherosclerosis and cerebrovascular disease, our data provide evidence that there is no association between these polymorphisms and the occurrence of cerebral aneurysms in Caucasians.

Copyright $@ 2003$ S. Karger AG, Basel

\section{Introduction}

The NADPH oxidase system is an important enzymatic origin of oxygen free radicals [1]. However, recent studies have shown that the NADPH oxidase system in nonphagocytic cells like vascular smooth muscle cells 
Table 1. Characterization of aneurysm patients

\begin{tabular}{ll}
\hline Patient characteristics & Value \\
\hline Male & 49 \\
Mean age, years & 54.0 (range 23-75) \\
\hline Female & 64 \\
Mean age, years & 54.5 (range 29-72) \\
\hline SAH & 99 \\
\hline Incidental & 14 \\
\hline Location & \\
ACA, A.com.ant. & 51 \\
MCA & 31 \\
ICA & 15 \\
PICA & 4 \\
BA & 7 \\
Others & 5 \\
Multiple & $11^{\mathrm{a}}$ \\
\hline Risk factors & \\
Former history of SAH & 0 \\
Familial history of SAH & 3 \\
Current or former smoker & 38 \\
Hypertension & 32 \\
\hline Treatment & 76 \\
Clipping & 37 \\
Endovascular procedure & \\
\hline
\end{tabular}

SAH = Subarachnoid hemorrhage; $\mathrm{ACA}=$ anterior cerebral artery; $\mathrm{MCA}=$ middle cerebral artery; ICA = internal carotid artery; $\mathrm{PICA}=$ posterior inferior cerebellar artery; $\mathrm{BA}=$ basilar artery .

a Seven patients had two aneurysms, 2 patients had three, 1 patient had five, and 1 patient had six aneurysms.

(VSMCs) and endothelial cells is the major source of superoxide anion [2]. p22phox is an important component in both phagocytic and nonphagocytic NADPH oxidase, forming the $\alpha$-subunit of the cytochrome $b_{558}$ which functions as the final electron transporter from NADPH and NADH to molecular oxygen in the system [3]. Oxygen free radicals in these compartments were found to be involved in the pathogenesis of atherosclerotic vascular disease $[4,5]$. Oxidative stress is induced in the vasculature by activation of redox-sensitive signaling pathways and stimulation of VSMC mitogenesis which contributes to atherogenesis. Remodeling of the extracellular matrix and atherosclerotic structural changes were found in the initial stages of intracranial aneurysm development $[6,7]$. Therefore, it is reasonable to investigate the major source of superoxide anion - the NADPH oxidase system - in patients with intracranial aneurysms.
Four polymorphisms of the p22phox gene have been reported in the literature, while another one, $381 \mathrm{~T}>\mathrm{C}$, is only listed in the single nucleotide polymorphism (SNP) databank (www.ncbi.nlm.nih.gov/SNP, dbSNP: 12123). Three of these $(381 \mathrm{~T}>\mathrm{C}, 480 \mathrm{G}>\mathrm{A}$, and $521 \mathrm{C}>\mathrm{T})$ are located in exon 6 , while one, $* 24 \mathrm{~A}>\mathrm{G}$, is located in the 3 -untranslated region ( 3 -UTR), and the $214 \mathrm{C}>\mathrm{T}$ polymorphism is located in exon 4 . There are controversial results on whether the $214 \mathrm{C}>\mathrm{T}$ polymorphism is associated with the occurrence of coronary artery disease [8-11]. Recently, this polymorphism was reported to be associated with the occurrence of cerebrovascular disease in a Japanese population [12]. Our aim was to investigate whether there is an association between the genotype and the phenotype in intracranial aneurysms. In addition, it is of interest to analyze the allele frequencies of these polymorphisms in different ethnic groups. Therefore, we investigated the allele and genotype frequencies and constructed haplotypes comprising five polymorphisms of the NADPH p22phox gene in a Caucasian population with intracranial aneurysms.

\section{Material and Methods}

\section{Study Population}

The patient group consisted of 113 unrelated, consecutively recruited patients with intracranial aneurysms ( 49 males, 65 females, mean age 54 (range 21-75) and 55 (range 27-82) years, respectively). All patients presented with at least one aneurysm, which was confirmed by cerebral angiography. They were all operated on or treated by an endovascular approach between 1997 and 1998 at the Departments of Neurosurgery and Neuroradiology, University of Technology, Dresden. All patients were residents of the Dresden urban area. Further details are listed in table 1.

The control groups consisted of 28 (14 male, 14 female) and 25 (13 male, 12 female) anonymous, healthy blood donors enrolled from the same urban area.

This study was approved by the local ethics committee. Informed written consent for genetic analysis was obtained from all patients.

\section{Determination of $214 C>$ T Polymorphism by Restriction}

Fragment Length Polymorphism

The 214C $>\mathrm{T}$ polymorphism generates a $R s a \mathrm{I}$ digestion site. Therefore, we decided to analyze this genomic site by restriction fragment length polymorphism analysis. Genomic DNA was amplified by polymerase chain reaction (PCR) using primers $5^{\prime}$-TGCTTGTGGGTAAACCAAGG-3' (sense), and 5'-GGAAAAACACTGAGGTAAGTG-3' (antisense) as previously described [11]. Both primers were Cy5 end-labeled. PCR conditions were: 1 cycle at $94^{\circ} \mathrm{C}$ for $3 \mathrm{~min} ; 35$ cycles of $1 \mathrm{~min}$ at $94^{\circ} \mathrm{C}, 1 \mathrm{~min}$ at $60^{\circ} \mathrm{C}$, and $1 \mathrm{~min}$ at $72^{\circ} \mathrm{C}$, followed by final extension at $72^{\circ} \mathrm{C}$ for $10 \mathrm{~min}$ in a Gene Amp PCR system 2400 (Perkin Elmer, Applied Biosystems GmbH, Weiterstadt, Germany). 
Fig. 1. Scheme of the NADPH p22phox gene presenting the 6 exons of the gene (E1E6) and their sizes in basepairs (bp). Positions are not in scale. The relative positions of the five polymorphisms are shown termed with the expression commonly used in the literature (upper line) and according to the nomenclature we refer to (lower line). In brackets, the amino acid codes and their position in the amino acid sequence are given. $\mathrm{UTR}=$ Untranslated region

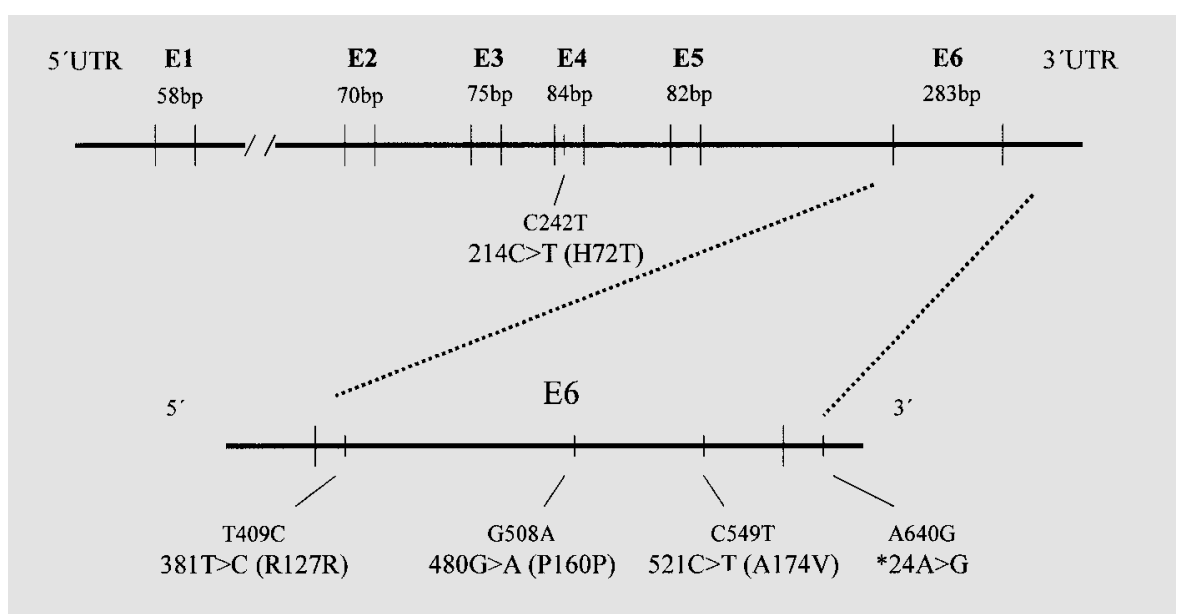

The PCR product ( $353 \mathrm{bp}$ ) was cleaved by RsaI (New England Biolabs, Inc., Beverly, Mass., USA) in the appropriate buffer. The enzyme does not cut wild-type DNA at that particular site. Digestion of the PCR product yields bands of $353 \mathrm{bp}$ in CC homozygotes (wildtype), 160 and $193 \mathrm{bp}$ in TT homozygotes, and all 3 bands in the heterozygous state. Fragments were resolved by electrophoresis on denaturing 6.5\% Long Ranger gels (FMC Bioproducts, Rockland, Me., USA) and analyzed using Fragment Manager ${ }^{\mathrm{TM}}$ (Pharmacia Biotech, Uppsala, Sweden) software.

\section{Sequence Analysis of Exon 6}

Polymorphisms $381 \mathrm{~T}>\mathrm{C}, 480 \mathrm{G}>\mathrm{A}, 521 \mathrm{C}>\mathrm{T}$, and $* 24 \mathrm{~A}>\mathrm{G}$ are located in exon 6 and the $3^{\prime}$-UTR, respectively. Therefore, we decided to investigate this genomic region by direct sequence analysis.

Following primers were used: 5'-GCTCAACCCTTCAGTGCC3' and 5'-CATTTATTGCAGGTGGGTGC-3' (Amersham Pharmacia Biotech, Erlangen, Germany). $1 \mu M$ of each primer (sense primer was cyanine 5 end-labeled) was mixed with $100 \mathrm{ng}$ of genomic DNA and $12.5 \mu \mathrm{l}$ PCR Master Mix (Promega, Madison, Wisc., USA) in a final volume of $25 \mu$.

Amplifying conditions were: initial denaturation at $95^{\circ} \mathrm{C}$ for $2 \mathrm{~min}$ followed by 40 cycles of denaturation at $95^{\circ} \mathrm{C}$ for $30 \mathrm{~s}$, annealing at $60^{\circ} \mathrm{C}$ for $30 \mathrm{~s}$ and extension at $72^{\circ} \mathrm{C}$ for $45 \mathrm{~s}$, completed by a final extension step at $72^{\circ} \mathrm{C}$ for 5 min using a thermal cycler (Perkin Elmer, Applied Biosystems GmbH). For negative control water was used instead of genomic DNA in PCR.

PCR products were electrophoresed on a $0.8 \%$ agarose gel, and bands were cut out and eluted. $3 \mu \mathrm{l}$ of the eluted PCR product were used in reaction mix where $1 \mu \mathrm{l}$ of Thermo Sequenase Mix (Amersham Pharmacia Biotech UK Ltd, Little Chalfont, UK) and $1 \mu M$ cyanine 5 end-labeled sense primer were added. Cycling reaction was performed under the following conditions using a thermo cycler: $95^{\circ} \mathrm{C}$ for $3 \mathrm{~min}$ followed by 25 cycles at $95^{\circ} \mathrm{C}$ for $30 \mathrm{~s}$ and at $65^{\circ} \mathrm{C}$ for $30 \mathrm{~s}$, followed by $72^{\circ} \mathrm{C}$ for $3 \mathrm{~min}$. Cycling products were run on ALFexpress ${ }^{\circledR}$ using denaturing $6.5 \%$ Long Ranger gels, which were run at $40 \mathrm{~W}(1,000 \mathrm{~V}, 38 \mathrm{~mA})$ for $4 \mathrm{~h}$. Runs were analyzed using ALF Evaluation $^{\mathrm{TM}}$ software.

Polymorphisms of the NADPH Oxidase p22phox Gene

\section{Statistical Methods and Study Course}

The size of the primary case sample was determined so that an allele frequency of $10 \%$ could be detected with a confidence of $97.5 \%$ without assuming Hardy-Weinberg equilibrium [13], thus limiting the overall error in both groups to $5 \%$. Hence, a primary sample of 35 cases and 28 controls was investigated.

Deviations from Hardy-Weinberg equilibrium were evaluated by comparing observed and expected genotype frequencies with an exact goodness of fit test in cases and controls, separately. To validate findings, a second sample of 78 cases was enrolled to detect the same deviation with a power of $90 \%$ at a nominal significance level of $5 \%$. Odds ratios (ORs) and exact 95\% confidence intervals (CIs) were calculated to compare allele frequencies [14] and genotype frequencies using the Cochrane-Armitage trend test.

Furthermore, haplotypes were constructed using the expectation maximization algorithm with subsequent haplotype testing via permutation tests [15].

\section{Nomenclature}

In the current literature polymorphisms of the NADPH p22phox gene are frequently termed according to the position of the concerned nucleotide in the mRNA sequence of this gene published in the GenBank database (http://www.ncbi.nlm.nih.gov: accession NM_000101). We refer to the nomenclature system recommended by den Dunnen and Antonarakis [16] and the Nomenclature Working Group 1998 (http://www.dmd.nl/mutnomen.html). In figure 1 the polymorphisms are depicted according to both nomenclatures.

\section{Results}

A total of 113 patients and 53 anonymous controls were enrolled in this study. Patient characteristics are summarized in table 1.

Genotype and allele frequencies of all five particular SNPs of the p22phox gene were determined in the primary sample comprising 35 patients and 28 controls. Their 
Table 2. Allele frequencies in the primary study sample

\begin{tabular}{|c|c|c|c|c|c|c|}
\hline \multirow[t]{2}{*}{ Locus } & \multirow[t]{2}{*}{ Allele } & \multicolumn{2}{|c|}{$\begin{array}{l}\text { Intracranial } \\
\text { aneurysm }(n=35)\end{array}$} & \multicolumn{2}{|c|}{$\begin{array}{l}\text { Control } \\
(\mathrm{n}=28)\end{array}$} & \multirow[t]{2}{*}{ OR $(95 \% \mathrm{CI})$} \\
\hline & & $\mathrm{n}$ & $\%$ & $\mathrm{n}$ & $\%$ & \\
\hline \multirow[t]{2}{*}{$214 C>T$} & M & 48 & 68.57 & 40 & 71.43 & \multirow[t]{2}{*}{$1.15(0.50-2.67)$} \\
\hline & $\mathrm{m}$ & 22 & 31.43 & 16 & 28.57 & \\
\hline \multirow[t]{2}{*}{$381 \mathrm{~T}>\mathrm{C}$} & M & 69 & 98.58 & 53 & 94.64 & \multirow{2}{*}{$0.26(0.00-3.33)$} \\
\hline & $\mathrm{m}$ & 1 & 1.42 & 3 & 5.36 & \\
\hline \multirow[t]{2}{*}{$480 \mathrm{G}>\mathrm{A}$} & $\mathrm{M}$ & 68 & 97.14 & 56 & 100.00 & \multirow[t]{2}{*}{$-(0.15-)$} \\
\hline & $\mathrm{m}$ & 2 & 2.86 & 0 & 0.00 & \\
\hline \multirow[t]{2}{*}{$521 \mathrm{C}>\mathrm{T}$} & M & 37 & 52.86 & 34 & 60.71 & \multirow[t]{2}{*}{$1.38(0.64-3.00)$} \\
\hline & $\mathrm{m}$ & 33 & 47.14 & 22 & 39.29 & \\
\hline \multirow[t]{2}{*}{$* 24 \mathrm{~A}>\mathrm{G}$} & M & 44 & 62.86 & 33 & 58.93 & \multirow[t]{2}{*}{$0.85(0.39-1.86)$} \\
\hline & $\mathrm{m}$ & 26 & 37.14 & 23 & 41.07 & \\
\hline
\end{tabular}

$\mathrm{M}=$ Major, more common allele; $\mathrm{m}=$ minor, less common allele; $\mathrm{OR}=$ odds ratio; $\mathrm{CI}=$ confidence interval.
Table 3. Genotype frequencies in the primary study sample

\begin{tabular}{|c|c|c|c|c|c|c|}
\hline \multirow[t]{2}{*}{ Locus } & \multirow[t]{2}{*}{ Genotype } & \multicolumn{2}{|c|}{$\begin{array}{l}\text { Intracranial } \\
\text { aneurysm }(n=35)\end{array}$} & \multicolumn{2}{|c|}{$\begin{array}{l}\text { Control } \\
(\mathrm{n}=28)\end{array}$} & \multirow[t]{2}{*}{ OR $(95 \% \mathrm{CI})$} \\
\hline & & $\mathrm{n}$ & $\%$ & $\mathrm{n}$ & $\%$ & \\
\hline \multirow[t]{3}{*}{$214 C>T$} & $\mathrm{M} / \mathrm{M}$ & 17 & 48.57 & 14 & 50.00 & \\
\hline & $\mathrm{M} / \mathrm{m}$ & 14 & 40.00 & 12 & 42.86 & $1.14(0.50-2.66)$ \\
\hline & $\mathrm{m} / \mathrm{m}$ & 4 & 11.43 & 2 & 7.14 & $1.30(0.25-7.06)$ \\
\hline \multirow[t]{3}{*}{$381 \mathrm{~T}>\mathrm{C}$} & $\mathrm{M} / \mathrm{M}$ & 34 & 97.14 & 25 & 89.29 & \\
\hline & $\mathrm{M} / \mathrm{m}$ & 1 & 2.86 & 3 & 10.71 & $0.25(0.00-3.33)$ \\
\hline & $\mathrm{m} / \mathrm{m}$ & 0 & 0.00 & 0 & 00.00 & \\
\hline \multirow[t]{3}{*}{$480 \mathrm{G}>\mathrm{A}$} & $\mathrm{M} / \mathrm{M}$ & 34 & 97.14 & 28 & 100.00 & \\
\hline & $\mathrm{M} / \mathrm{m}$ & 0 & 0.00 & 0 & 0.00 & \\
\hline & $\mathrm{m} / \mathrm{m}$ & 1 & 2.86 & 0 & 0.00 & $-(0.02-)$ \\
\hline \multirow[t]{3}{*}{$521 \mathrm{C}>\mathrm{T}$} & $\mathrm{M} / \mathrm{M}$ & 13 & 37.14 & 12 & 42.86 & \\
\hline & $\mathrm{M} / \mathrm{m}$ & 11 & 31.43 & 10 & 35.71 & $1.27(0.66-2.51)$ \\
\hline & $\mathrm{m} / \mathrm{m}$ & 11 & 31.43 & 6 & 21.43 & $1.62(0.43-6.28)$ \\
\hline \multirow[t]{3}{*}{$* 24 \mathrm{~A}>\mathrm{G}$} & $\mathrm{M} / \mathrm{M}$ & 13 & 37.14 & 11 & 39.29 & \\
\hline & $\mathrm{M} / \mathrm{m}$ & 18 & 51.43 & 11 & 39.29 & $0.85(0.39-1.84)$ \\
\hline & $\mathrm{m} / \mathrm{m}$ & 4 & 11.43 & 6 & 21.43 & $0.73(0.15-3.40)$ \\
\hline
\end{tabular}

$\mathrm{M}=$ Major, more common allele; $\mathrm{m}=$ minor, less common allele; $\mathrm{OR}=$ odds ratio; $\mathrm{CI}=$ confidence interval. distribution in both groups and results from the comparisons of allele and genotype frequencies are presented in tables 2 and 3 .

No deviation from Hardy-Weinberg equilibrium was detected at polymorphisms $214 \mathrm{C}>\mathrm{T}$ and $* 24 \mathrm{~A}>\mathrm{G}$ in either group, and at the $521 \mathrm{C}>\mathrm{T}$ polymorphism in the control group (all nominal $p>0.05$ ). In the case group, how- ever, Hardy-Weinberg disequilibrium was found at the $521 \mathrm{C}>\mathrm{T}$ polymorphism (nominal $\mathrm{p}=0.0399$ ). To validate this finding, a second sample of 78 cases was enrolled to detect the same deviation with a power of $90 \%$ at a nominal significance level of 5\%. This sample did not reveal deviation from Hardy-Weinberg equilibrium (nominal $\mathrm{p}>0.05)$. 
Table 4. Haplotypes constructed out of polymorphisms $214 \mathrm{C}>\mathrm{T}$, $521 \mathrm{C}>\mathrm{T}$, and $* 24 \mathrm{~A}>\mathrm{G}$

\begin{tabular}{|c|c|c|c|c|c|c|}
\hline \multicolumn{3}{|c|}{ Genotype $^{a}$} & \multicolumn{2}{|c|}{ Cases } & \multicolumn{2}{|c|}{ Controls } \\
\hline $214 C>T$ & $521 \mathrm{C}>\mathrm{T}$ & $* 24 \mathrm{~A}>\mathrm{G}$ & $\mathrm{n}$ & $\%$ & $\mathrm{n}$ & $\%$ \\
\hline 1 & 1 & 2 & 4 & 11.4 & 0 & 0.0 \\
\hline 1 & 1 & 3 & 3 & 8.6 & 4 & 14.3 \\
\hline 1 & 2 & 2 & 5 & 14.3 & 5 & 17.9 \\
\hline 1 & 3 & 1 & 5 & 14.3 & 5 & 17.9 \\
\hline 2 & 1 & 2 & 3 & 8.6 & 2 & 7.1 \\
\hline 2 & 1 & 3 & 1 & 2.9 & 0 & 0.0 \\
\hline 2 & 2 & 2 & 6 & 17.1 & 3 & 10.7 \\
\hline 2 & 2 & 3 & 0 & 0.0 & 2 & 7.1 \\
\hline 2 & 3 & 1 & 4 & 11.4 & 5 & 17.9 \\
\hline 3 & 3 & 1 & 4 & 11.4 & 1 & 3.6 \\
\hline 3 & 3 & 2 & 0 & 0.0 & 1 & 3.6 \\
\hline Total & & & 35 & & 28 & \\
\hline
\end{tabular}

Empirical significance level from 1,000 permutations using $\chi^{2}$ statistic for model-free analysis $=11.38, \mathrm{df}=8, \mathrm{p}=0.2030(\mathrm{NS})$.

a $\quad 1=$ Major $/$ major allele; $2=$ major $/$ minor allele; $3=$ minor $/$ minor allele.

In addition, allele and genotype frequencies of this second sample of cases were compared with a second sample of controls $(n=25)$, which confirmed the results of the first study sample (data not shown).

Certainly, it would have been interesting to base the calculation of the size of a validation sample not on detecting deviations from Hardy-Weinberg equilibrium but on detecting differences in allele frequencies between cases and controls calculated from the first sample. However, as the frequencies of the $\mathrm{T}$ allele were similar in cases and controls (32.86 and $28.57 \%$, respectively), 2,030 cases and 2,030 controls would have been required to detect this difference with a power of $90 \%$.

Haplotypes were constructed regarding the three most frequent polymorphisms $(214 \mathrm{C}>\mathrm{T}, 521 \mathrm{C}>\mathrm{T}$, and $* 24 \mathrm{~A}>\mathrm{G}$ ) for the total sample. Genotypes and their distribution between cases and controls are shown in table 4 . Haplotype frequencies in cases and controls were not significantly different $(\mathrm{p}=0.203)$.

\section{Discussion}

The NADPH oxidase system is a major source of superoxide anion formation. Oxygen free radicals are involved in tissue remodeling and atherogenesis, and superoxide reaction products were detected in initial stages of cerebral aneurysm. The genetic background of these findings is unclear. Our aim was to investigate whether polymorphisms of the NADPH oxidase $p 22 p h o x$ gene are associated with the phenotype, an intracranial aneurysm. In our analysis, we have not found an association of either the $214 \mathrm{C}>\mathrm{T}$ polymorphism or polymorphisms located in and around exon 6 of the NADPH oxidase $p 22 p h o x$ gene with the occurrence of cerebral aneurysms in a Caucasian population.

The NADPH oxidase system was originally described in phagocytes $[17,18]$. Recent studies provide evidence that the NADPH oxidase is also present in nonphagocytic cells $[3,19,20]$. $\mathrm{p} 22$ phox is one of five proteins forming the NADPH core enzyme, and is a critical component of the NADPH oxidase system in VSMCs. Mutations in the human neutrophil cytochrome b light chain (p22phox) are associated with chronic granulomatous disease [21]. In addition, four types of polymorphisms of the p22phox gene have been reported and are discussed in the literature. The $214 \mathrm{C}>\mathrm{T}$ polymorphism, located in exon 4 of the p22phox gene, results in an amino acid exchange, histidine-72 by tyrosine, in the heme-binding region of the protein. The $381 \mathrm{~T}>\mathrm{C}$, and $480 \mathrm{G}>\mathrm{A}$ polymorphisms do not affect amino acid sequences, while $521 \mathrm{C}>\mathrm{T}$ changes alanine to valine at codon 174 , and $* 24 \mathrm{~A}>\mathrm{G}$ is located in the $3^{\prime}$-UTR of the gene, $24 \mathrm{bp}$ downstream of the stop codon. The clinical significance of these polymorphisms is controversial [8-11].

These conflicting results could be explained by ethnicrelated differences, in addition to differences in study design, choice and size of study samples. The possible impact of racial/ethnic differences on allele frequencies of polymorphisms was previously shown by us, analyzing the endoglin gene [22].

In a Japanese population, a significant correlation between the polymorphic allele of the $214 \mathrm{C}>\mathrm{T}$ polymorphism and CVD was reported [12]. To our knowledge, confirmation of these results in another ethnic group has not been published. However, the findings by Ito et al. [12] confirm previous results by Walder et al. [23] who reported that the extent of ischemic stroke injury is reduced in NADPH oxidase-deficient mice. In our study, we did not find an association between the $214 \mathrm{C}>\mathrm{T}$ polymorphism and the occurrence of cerebral aneurysms, suggesting either that this particular polymorphism has a specific disease-related meaning for CVD, or that we cannot detect a difference between cases and controls in our aneurysm study because of racial/ethnic differences between Japanese and Caucasian healthy individuals. In- 
deed, a comparison of genotype frequencies between our Caucasian controls and the Japanese control group reported by Ito et al. [12] revealed a difference: frequencies for the wild-type/wild-type genotype 0.50 in our controls vs. 0.87 in the Japanese controls (nominal exact $\mathrm{p}<$ 0.0001). However, it is possible that we failed to detect a difference between cases and controls in our population, as the power of our study was only $17 \%$ in relation to the data of the Japanese study. To detect the difference reported by Ito et al. [12] with a power of $90 \%, 370$ cases and 370 controls would have been required.

Nevertheless, our results do not exclude that this particular gene might be involved in aneurysm pathogenesis as the effect might be smaller than in the Japanese study. Furthermore, we only analyzed a part of the gene. In addition to p22phox, the other components of the NADPH oxidase complex harbor genetic variants, which also might contribute to an altered superoxide production in the vascular wall, and thus may contribute to aneurysm genesis.

However, we have shown that frequent polymorphisms of the p22phox gene located in the open reading frame and the 3'-UTR, which have been associated with vascular diseases, are not associated with intracranial aneurysms in our Caucasian population.

\section{Acknowledgement}

This study was supported in part by a grant from the Deutsche Forschungsgemeinschaft (DFG) No. 1538/3-1. We are grateful to Mrs. U. Neumeister for her outstanding technical assistance and Mrs. S. Faatz for preparing the manuscript.

\section{References}

1 Dinauer MC: The respiratory burst oxidase and the molecular genetics of chronic granulomatous disease. Crit Rev Clin Lab Sci 1993;30: 329-369.

2 Babior BM: NADPH oxidase: An update. Blood 1999;93:1464-1476.

3 Ushio-Fukai M, Zafari AM, Fukui T, Ishizaka $\mathrm{N}$, Griendling KK: p22phox is a critical component of the superoxide-generating NADH/ NADPH oxidase system and regulates angiotensin II-induced hypertrophy in vascular smooth muscle cells. J Biol Chem 1996;271: 23317-23321.

4 Cahilly C, Ballantyne CM, Lim DS, Gotto A Marian AJ: A variant of p22(phox), involved in generation of reactive oxygen species in the vessel wall, is associated with progression of coronary atherosclerosis. Circ Res 2000;86: 391-395.

5 White CR, Brock TA, Chang LY, et al: Superoxide and peroxynitrite in atherosclerosis. Proc Natl Acad Sci USA 1994;91:1044-1048.

6 Bruno G, Todor R, Lewis I, Chyatte D: Vascular extracellular matrix remodeling in cerebral aneurysms. J Neurosurg 1998;89:431-440.

7 Chyatte D, Lewis I: Gelatinase activity and the occurrence of cerebral aneurysms. Stroke 1997; 28:799-804.

8 Cai H, Duarte N, Wilcken DE, Wang XL: NADH/NADPH oxidase p22 phox C242T polymorphism and coronary artery disease in the Australian population. Eur J Clin Invest 1999;29:744-748.
9 Li A, Prasad A, Mincemoyer R, Satorius C, Epstein N, Finkel T, Quyyumi AA: Relationship of the C242T p22phox gene polymorphism to angiographic coronary artery disease and endothelial function. Am J Med Genet 1999;86:57-61.

10 Gardemann A, Mages P, Katz N, Tillmanns H, Haberbosch W: The p22 phox A640G gene polymorphism but not the $\mathrm{C} 242 \mathrm{~T}$ gene variation is associated with coronary heart disease in younger individuals. Atherosclerosis 1999;145: 315-323.

11 Inoue N, Kawashima S, Kanazawa K, Yamada S, Akita H, Yokoyama M: Polymorphism of the NADH/NADPH oxidase p22 phox gene in patients with coronary artery disease. Circulation 1998;97:135-137.

12 Ito D, Murata M, Watanabe K, Yoshida T, Saito I, Tanahashi N, Fukuuchi Y: C242T polymorphism of NADPH oxidase p22 PHOX gene and ischemic cerebrovascular disease in the Japanese population. Stroke 2000;31:936939.

13 Gregorius $\mathrm{H}$ : The probability of losing an allele when diploid genotypes are sampled. Biometrics 1980;36:643-652.

14 Mehta C, Patel N, Gray R: On computing an exact confidence interval for the common odds ratio in several $2 \times 2$ contingency tables. $\mathrm{J}$ Am Stat Assoc 1985;392:969-973

15 Zhao JH, Curtis D, Sham PC: Model-free analysis and permutation tests for allelic associations. Hum Hered 2000;50:133-139.

16 den Dunnen JT, Antonarakis SE: Nomenclature for the description of human sequence variations. Hum Genet 2001;109:121-124.
17 Dinauer MC, Orkin SH, Brown R, Jesaitis AJ, Parkos CA: The glycoprotein encoded by the $\mathrm{X}$-linked chronic granulomatous disease locus is a component of the neutrophil cytochrome $b$ complex. Nature 1987;327:717-720.

18 Teahan C, Rowe P, Parker P, Totty N, Segal AW: The X-linked chronic granulomatous disease gene codes for the beta-chain of cytochrome b-245. Nature 1987;327:720-721.

19 Griendling KK, Ushio-Fukai M: Redox control of vascular smooth muscle proliferation. J Lab Clin Med 1998;132:9-15.

20 Mohazzab KM, Kaminski PM, Wolin MS: $\mathrm{NADH}$ oxidoreductase is a major source of superoxide anion in bovine coronary artery endothelium. Am J Physiol 1994;266:H2568H2572.

21 Dinauer MC, Pierce EA, Bruns GA, Curnutte JT, Orkin SH: Human neutrophil cytochrome b light chain (p22-phox). Gene structure, chromosomal location, and mutations in cytochrome-negative autosomal recessive chronic granulomatous disease. J Clin Invest 1990;86: 1729-1737.

22 Krex D, Ziegler A, Schackert HK, Schackert G: Lack of association between endoglin intron 7 insertion polymorphism and intracranial aneurysms in a white population: Evidence of racial/ethnic differences. Stroke 2001;32:26892694.

23 Walder CE, Green SP, Darbonne WC, Mathias J, Rae J, Dinauer MC, Curnutte JC, Thomas GR: Ischemic stroke injury is reduced in mice lacking a functional NADPH oxidase. Stroke 1997;28:2252-2258. 